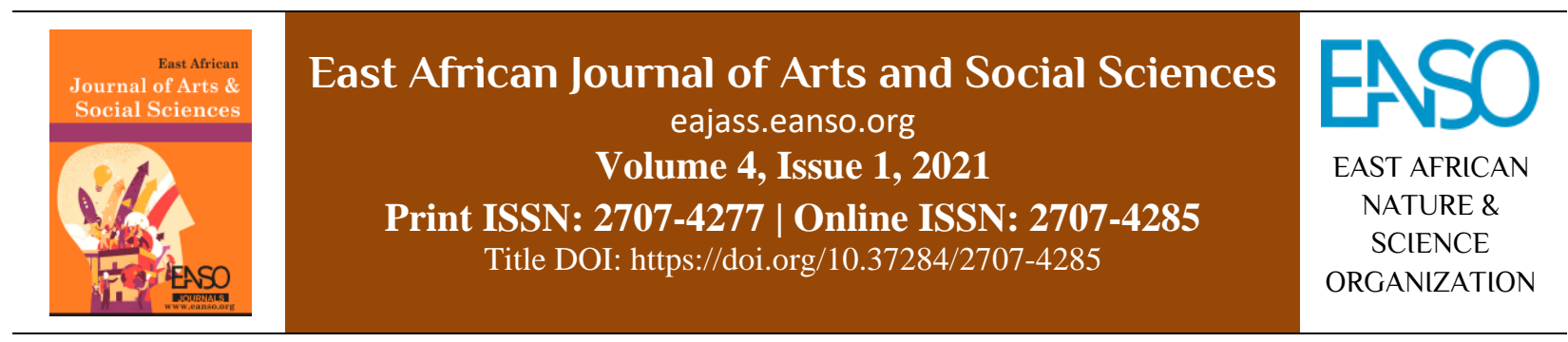

Original Article

\title{
Ethical Considerations for Community Based Psychosocial Accompaniment: Towards a Strengthened Mental Health Response amidst Covid-19 Pandemic.
}

\author{
Dr. Telesia Kathini Musili, $P h D^{1} \&$ Dr. Fancy Cheronoh, $P h D^{1}$ \\ ${ }^{1}$ Department of Philosophy and Religious Studies, University of Nairobi, P. O. Box 30197-00100, Nairobi, Kenya. \\ * ORCID ID: https://orcid.org/0000-0002-9448-7571; Correspondance email : telesia.musili@uonbi.ac.ke.
}

Article DOI: https://doi.org/10.37284/eajass.4.1.433

\section{Date Published: ABSTRACT}

12 October 2021 The outbreak of the Covid-19 pandemic in the early months of 2020 thwarted and continues to disrupt the strides made in the provision of health services including

Keywords: mental health. Mental health stability is vital to personal wellbeing, the building Community-based; of relationships and the making of notable contributions to society. This paper Covid-19, sought to situate the importance of psychosocial accompaniment within the Ethics. community as one of the strategies of responding to mental health challenges that Mental health; are usually compounded by stigma and discrimination. Content analysis of Psychosocial relational actions prompted by the infectious Covid-19 pandemic formed the basis Accompaniment. of this article. Ethical considerations of justice and mutual trust are advanced as foundational values in a community of relations that can easily and practically respond to mental health instability amidst contagious epidemics. The study employed reported experiences of distress emanating from life disruptions that significantly led to poorer mental health in order to urge for psychosocial accompaniment that is founded within the community level. Close relations within the community are lauded as a practical strategy of enhancing and strengthening mental health response amidst contagious pandemics, such as Covid-19.

\section{APA CITATION}

Musili, T. K., \& Cheronoh, F. (2021). Ethical Considerations for Community Based Psychosocial Accompaniment: Towards a Strengthened Mental Health Response amidst Covid-19 Pandemic. East African Journal of Arts and Social Sciences, 4(1), 110. https://doi.org/10.37284/eajass.4.1.433

\section{CHICAGO CITATION}

Musili, Telesia Kathini and Fancy Cheronoh. 2021. "Ethical Considerations for Community Based Psychosocial Accompaniment: Towards a Strengthened Mental Health Response amidst Covid-19 Pandemic". East African Journal of Arts and Social Sciences 4 (1), 1-10. https://doi.org/10.37284/eajass.4.1.433. 


\section{HARVARD CITATION}

Musili, T. K., \& Cheronoh, F. (2021) "Ethical Considerations for Community Based Psychosocial Accompaniment: Towards a Strengthened Mental Health Response amidst Covid-19 Pandemic", East African Journal of Arts and Social Sciences, 4(1), pp. 1-10. doi: 10.37284/eajass.4.1.433.

\section{IEEE CITATION}

T. K. Musili, \& F. Cheronoh. "Ethical Considerations for Community Based Psychosocial Accompaniment: Towards a Strengthened Mental Health Response amidst Covid-19 Pandemic”, EAJASS, vol. 4, no. 1, pp. 1-10, Oct. 2021.

\section{MLA CITATION}

Musili, Telesia Kathini \& Fancy Cheronoh. "Ethical Considerations for Community Based Psychosocial Accompaniment: Towards a Strengthened Mental Health Response amidst Covid-19 Pandemic". East African Journal of Arts and Social Sciences, Vol. 3, no. 1, Oct. 2021, pp. 1-10, doi:10.37284/eajass.4.1.433.

\section{INTRODUCTION}

The outbreak of the Covid-19 pandemic in the early months of 2020 met a scenario of unpreparedness both for the national governments and the populace. Governments at both international and national levels grappled with mitigating its spread by putting in place measures and interventions such as lockdown restrictions, quarantines, physical and social distancing. The consequences of Covid-19 affected every dimension of human life ranging from economic, social, ethical and psychological to spiritual wellbeing. Governments and their entire populace woke up to increasing distress, worries, fears and uncertainties presenting themselves as a new virus worth addressing. Sexual and genderbased violence hit its highest, mental health problems and hunger ravaged societies. In Kenya, for instance, as Covid-19 infections rose by day, humanitarian aid in monetary forms and in-kind streamed into the country through the government, non-governmental organizations and Faith-Based organizations. In such situations, psychosocial mitigation is called for since the citizens' wellbeing and ability to function is directly connected to the social environment and the psychological components that inform compliance and adherence to laid down interventions.

As chaos ravaged families, ranging from hurried burials, social and physical distancing of sickly family members and relatives, loss of jobs and braving 'new' environments, especially for house heads, mental instability crept in. Heightened emotions resulting from the disturbance of what has always been the 'normalcy' coupled with bottled up grief led to stress and depression among the populace as attested by the rate of relational violence within homes. Family members rose against each other; husband and or wife against each other, siblings hurting each other as well as grown children hurting their grandparents and parents. Onyango et al. (2019) note that epidemic seasons always lead to increased violence among intimate partners and an upsurge of unintended pregnancies. John et al. (2021, p. 55) further corroborate it with their assertion that "pandemics and governmentimposed restrictions to control them, such as quarantines and school closures, exacerbate genderbased inequalities and increases the exposure of women and girls to gender-based violence (GBV)."

During the lockdown period in Kenya that saw many people work from home, surging cases of killings among spouses, incest rapes and suicide, among other ills were reported. The consequences are usually traumatic, which take a long-term toll on mental and psychological health. Traumatic experiences create long-term negative emotional imbalance, which in turn affects not only the person going through the experience but also the society in general. In Kenya, mentally sick persons are often times dragged forcefully to health centres when they are not even conscious of their ailment. Systems to identify and address mental health breakdown and emotional imbalance at their initial stages are lacking. Support systems often forget or ignore the flare-ups of negative emotions prompted by these distressing violence occurrences (Marangu et al., 2021). This article highlights the mental health situation in Kenya during the pandemic and discusses the art of psychosocial accompaniment. It further revisits the ethics of psychosocial accompaniment of citizens, braving the magnitude of the Covid-19 pandemic taking into account mental health issues and concerns; towards a bottom-up, communal to national and community to 
health centres/hospital approach in addressing mental health issues.

\section{MENTAL HEALTH SITUATION IN KENYA DURING COVID-19 PANDEMIC}

The World Health Organization (WHO) (March 30 2018) defines mental health as "a state of wellbeing in which an individual realizes his or her own abilities, can cope with the normal stresses of life, can work productively and is able to make a contribution to his or her community." The proper functioning of any society is thus anchored, among other pillars, on the mental wellbeing of its population. It is an important resource to the social, economic, political and cultural development of society. Ill health witnessed during the Covid-19 pandemic disturbed the proper functioning of a society. Kenya reported its first positive case of Covid-19 on March 132020 in a 27-year-old woman who had travelled from the United States via London. The report elicited fear, anxiety and panic among Kenyans. In view of containing the spread of the virus, the Kenyan government instituted measures such as imposing the first national curfew between 7 pm and 5 am daily on March 272020. Movement restrictions in and out of some counties (Nairobi, Mombasa, Kwale, Kilifi, Nakuru, Kiambu, Kajiado) which were considered disease hotspots, were issued.

The government of Kenya issued containment measures such as working from home, social distancing, isolation and quarantine that caused distress and depression. Most people were/are afraid of infection, dying or losing loved ones. Thrown into a contained shared space, incest rapes, intimate violence and suicide cases became the order of the day. Closure of learning institutions and workplaces except for essential service providers led to disruption in routine which has further heightened distress levels in most people. Loss of income, source of livelihood and economic constraints generally graven the situation. Fear of the unknown and uncertainty about the future exacerbated the situation. The homes that were thought to be safe havens proved to be dangerous spaces.

Consequently, many cases pointing to mental health distress crept into society. As such, "cases of violence targeting women and girls - including rape, child marriage and murder - rose from $36 \%$ in 2020 from a year earlier to just over 5,000" (Bhalla, 2021); whilst national television channels reported that at least four hundred and eighty-three (483) Kenyans had committed suicide between the month of May-August 2021 (National Television, 2021). On average, about one hundred and fifty (150) Kenyans commit suicide monthly. However, considering that suicide is criminalized in Kenya and a bad omen in most of the tribes in the country, underreporting and misreporting of suicide-related deaths is common (Kenya Penal Code, 2012). Mental health cases that end up in suicide are thus not made public because of the stipulated punishment of about two years in jail, stigma and discrimination that is deeply entrenched in our culture. This implies that the statistics might be more than what is often reported thus, making it difficult to come up with accurate findings.

Scholars in psychology and mental health continue to advocate for the revision of the Kenyan law that decriminalizes suicide and suicidal attempts (Bitta et al., 2018; Marangu et al., 2014; Kokonya et al., 2007). Lack of proper tracking systems and capacity for managing mental health issues in the country, among other challenges were further aggravated by the Covid-19 pandemic. The social support systems towards mental health response crumbled due to reduced social interaction hence an increase in selfharm, violence and surging suicide rates. The pandemic disrupted one of the most sensitive rites of passage directly related to mental wellbeing. Death and burial are generally an elaborate rite of passage among Kenyans and most of Africa due to their belief in life after death. The dead are thus handled carefully lest they harm the living from their spiritual world. Hastened burials for those who succumbed to Covid-19, sometimes late in the night or early in the morning, with or without family members, caused socio-cultural disruption. The deceased families have had to encounter psychological and spiritual distress following poor burial processes that ignored the traditions and customs of the society. The media (print, social and electronic) was saturated with such reports showing how some widows were left with unanswered questions when their husbands were hurriedly buried against the accustomed burial rites befitting them. The disruptive scenario prompted by Covid19 further destabilized mental stability and 
wellbeing. The situation laid bare the need for psychosocial accompaniment to overcome stigma, bereavement, fear and worries emanating from the 'new normal' since mental health "is more than the absence of mental disorders" (WHO, 2020). Mental health stability is vital to personal wellbeing, building relationships and making contributions to society (Saxena, Saraceno \& Granstein, 2013).

The United Nations policy brief of May 132020 noted that "although the Covid-19 crisis is, in the first instance, a physical health crisis, it has the seeds of a major mental health crisis as well if action is not taken." Unfortunately, most governments had not invested in mental health promotion, prevention and care prior to the pandemic, a fact further noted in the UN policy brief. Kenya, for instance, has only one mental referral facility, Mathari hospital, where one nurse handles up to 150 patients (Jenkins et al., 2010). Furthermore, it has a shortage of mental health professionals with approximately 100 psychiatrists serving a population of 45 million people (WHO's Mental Health Atlas, 2015). It is worth noting that a third of these psychiatrists work in government health facilities while the rest work in private facilities where consultation fees are exorbitant, thus denying a majority of the population access to mental health services.

The situation is further exacerbated by low budget allocation to mental health by the Kenyan Government which is about $0.05 \%$ of the health budget (Mutiso et al., 2018). Communicable diseases and terminal illnesses such as cancer have largely been given a priority in the health budget neglecting an important sector of mental health. Though the Kenyan government launched mental health policy in 2016 which provided for the integration of mental health services with other health services, the policy is yet to be fully adopted taking into account the aforementioned poor funding and shortage of mental health professionals. In addition, Kenya devolved health services to its 47 counties allowing each county to prioritize its health services and budget allocations according to the specific contexts and health needs of its people. Consequently, mental health services are pushed at the lower order of spectrum with prominence given to 'fatal' diseases such as cancer and kidney diseases, just to mention a few.
The rising levels of mental health and related issues such as depression, suicide and self-harm are not given much attention yet "it is undeniable that the fear of uncertain future and stigma of Covid-19 is fuelling mental health crisis in Kenya" (Ochillo \& Elsie, 2020). The need to prioritize mental health, especially at the community level during this pandemic cannot thus be overemphasized. UN Policy Brief of May 2020 on the need for action on mental health recommended three action points to minimize the mental health consequences of the pandemic. Among such actions is to ensure the widespread availability of emergency mental health and psychosocial support.

In Kenya, the Ministry of Health (MOH) has continued to offer guidelines on mental health care and psychosocial support during the Covid-19 pandemic. One such document is a comprehensive guide prepared for health workers outlining the necessary steps to be taken while offering mental health services and psychosocial support to the diverse categories of people, namely: the general population, people on treatment for Covid-19, those in quarantine and isolation, people with mental health conditions requiring care in these settings and health workers $(\mathrm{MOH}, 2020)$. While highlighting the formal response, particularly for the health workers, there is a need to consider psychosocial support emanating from the community taking into account that most people seek mental health services when their situations have worsened.

The reality, at least in the Kenyan context, is that most people who present mental health issues such as anxiety, stress, insomnia and depression do not seek mental health services in hospitals. Some seek help from family members, friends, relatives, religious circles, and workmates and community support systems generally. There is a need, therefore, for a model that provides psychosocial support from the community through available social work systems before one gets help from professionals in the hospitals. Community health workers in conjunction with the family members and other close relations would form a promising bottom up-approach to mental health care tracing, support and escalation to health centres. Jaguga and Kwobah (2020, p. 1) proposed four formalized strategies for strengthening mental health responses 
during the Covid-19 pandemic in Kenya. They include

... (1) preparation of a formal mental health response plan specific to the COVID-19 pandemic with allocation of funding for the response (2) training of community health workers and community health volunteers on psychological first aid to enable access to support for those in need during the pandemic (3) scaling up of mobile health to increase access to care (4) conducting systematic and continuous text message surveys on the mental health impact of the COVID-19 pandemic in order to inform decision-making.

The proposed strategies are visionary and would go a long way in strengthening mental health in Kenya. However, the economic input that is anticipated to necessitate their implementation is a looming challenge given the economic standing in the country. A community-oriented strategy that is founded on the value of communality, oneness and being a brother's/sister's keeper would chart a practical and achievable strategy.

Various studies such as those of Ochillo and Elsie (2020), Wang et al. (2020), Plomecka et al. (2020), among others have underscored the mental health impact of the Covid-19 pandemic on the general population. The significance of psychosocial support, particularly towards community mental health response during the pandemic, however, remains understudied hence the present study. Psychosocial accompaniment to patients generally has shown a positive impact on their mental wellbeing. A study by Thomson et al. (2014), for instance, found out that the addition of communitybased accompaniment was associated with an additional $44.3 \%$ reduction in the prevalence of depression among HIV-infected adults. One can only envisage the positive impact of psychosocial accompaniment to persons with mental health issues and the public in general during a pandemic like Covid-19, where social distancing, quarantine and lockdowns have become a 'new normal', prompting loneliness. In order to appreciate the need for psychosocial accompaniment, some ethical considerations are vital in envisioning a bottom-up (from community to health centres) approach to strengthening mental health response and care.

\section{Psychosocial Accompaniment in the Context of Covid-19}

The concept and art of accompaniment have their origins from liberation theologies of Latin America, where it is directly associated with deliberately opting for the poor and the suffering in the society (Farmer, 2011; Gutiérrez, 1983; Goizueta, 2009). The concept of accompaniment continues to be embraced in envisioning an all-inclusive world. Pope Francis while reiterating the Roman Catholic stance on euthanasia in Samaritanus bonus (2020), stressed the importance of accompaniment amongst those who suffer in silence. The lone state prompted by Covid-19 prevention protocols of quarantining meant that people would in solitude bear their pain silently in a bid to protect themselves and close relations. Farmer (2013, p. 234) notes that to accompany someone

...is to go somewhere with him or her, to break bread together, to be present on a journey with a beginning and an end. There is an element of mystery, of openness, of trust, in accompaniment. The companion, the accompagnateur, says: "I'll go with you and support you on your journey wherever it leads. I'll share your fate for a while-and by " $a$ while," I don't mean a little while. Accompaniment is about sticking with a task until its deemed completed-not by the accompagnateur, but by the person being accompanied.

Accompaniment involves a relenting commitment and support in solidarity with the marginalized, the destitute, lonely and the suffering. Watkins (2015, p. 326) notes that it "occurs in communities that are struggling with various collective traumas, including poverty, violence, forced migration, racism, and environmental assault." It is an accompaniment characterized by objective concern for actioned care for the other, irrespective of the limiting factors. The Covid-19 pandemic has unearthed compounding traumas that have farreaching implications for the psychological wellbeing of human beings. The implications range from compromised decision-making capabilities, stigma and discrimination, inability to provide basic needs and consequently violence prompted by 
contravention of safety guidelines in the Covid-19 as well as social and sexual gender-based violence.

Destabilizing the psychological competencies of persons who are social in nature calls for an appropriate strategy that would counter adverse effects resulting from ill choices. As such, a psychosocial approach that "looks at individuals in the context of the combined influence that psychological factors and the surrounding social environment have on their physical and mental wellness as well as their ability to function" is called for (Woodward et al., 2015, p. 4). For instance, after physical and social distancing was enforced, the political class brandished it, holding meetings that the common citizen could not. Those in power were left off the hook, as the 'powerless' faced the wrath of the police to the point of spending cold nights in cells. As a result, deviance to the norm started creeping in, endangering the lives of the populace, not only to the pandemic but also physical harm witnessed in the hands of the men in uniform. It is in such circumstances where psychosocial accompaniment is called for in constructing allencompassing spaces characterized by a yearning desire to build values of trust, mutual respect and solidarity.

Watkins (2017, p. 17) argues that psychosocial accompaniment cannot be productive "from above, from a position of professional expertise." In a topdown form of accompaniment, power and privilege enhance the chances of corrupting the structures. Psychosocial accompaniment requires radical availability, steadfast witnessing, mutual dialogue, self-reflexivity, atonement to others' needs and desires and committed response-ability. In the context of Covid-19, the government as a collective body has a responsibility of accompanying the citizens in a manner that builds trust towards a responsive adherence to the interventions. For instance, in Kenya, a policewoman was seen on national television escorting a mother with a newborn to a bus stop during curfew time. In events where the national government faced challenges keeping up with this expectation, a devolved accompaniment at the community level would instil trust and adherence to the preventive protocols.

The fight to contain Covid-19 has, however, seen unprecedented growth of mistrust in a large proportion of the population towards the elite class - experts, politicians, decision-makers and health professionals, especially in Kenya, who not only fraught preventive protocols but are also involved in corruption. The moment is therefore decisive because, if the Covid-19 pandemic is overcome in the environment of growing mistrust, a culture of ethical corruption will permeate the society now and beyond. Corrupt instances have been reported by the media, sending ripple waves of corruption in the country. For instance, a whooping Kshs. 7.6 billion Covid-19 scandals were revealed by a television station in Kenya, with fraudulent procurement procedures, exorbitant face-mask prices, costly beverages and refreshments as well as selfpreservation schemes at the expense of the value of solidarity and trust (National Television, 2020). Amidst frustrations, one citizen humorously opined that "they (referring to the government and ministry of health) told us to put on a mask, cover our mouths so that they could eat alone!" (Ibid). Ironically, Kenyans continued to be arrested and placed under mandatory quarantine, paying their isolation expenses, treatment charges and in some cases even death. As a result, people's adherence to some interventions declined due to the perception that a minority was getting rich while the majority languished in lack and depression.

Movement restrictions and social distancing guidelines were further perceived to exclude politicians who continue flouting them by holding public gatherings. This led to the Chief Administrative Secretary in the Ministry of Health, Dr. Rashid Aman, confessing to the media that "we have no control over politicians and leaders who go against the Covid-19 protocols." Such a confirmation questions the integrity and commitment of the leaders in the country. Instead of embracing the value of solidarity in accompanying citizens in the advent of the pandemic, people were further pushed to the periphery, widening the gap between the privileged and the underprivileged. Furthermore, the ministry of education continued to advocate for virtual classes through technologymediated learning, leaving behind pupils and students who are in remote areas without power and modern gadgets (phones, radios, television).

Delivery of health care services was highly disrupted especially sexual and reproductive health 
services. Pre-natal and ante-natal services were wanting, with the media reporting women, for instance, giving birth by the roadside, outside hospital compounds amongst other cases due to shifting of resources to address the pandemic. HIV patients missed out on their antiretroviral medication during the pandemic prompting adverse effects. When disparity stands out within a community that treasures the value of communality, a breakdown of moral fibre is witnessed. As a deterrent, ethical principles undergirding psychosocial accompaniment are called for as discussed below.

\section{Ethics of Psychosocial Accompaniment}

Ethical principles governing psychosocial accompaniment depart from an inter-relational understanding of the subject and the societal institutions in question. First is the consideration of the subject as a moral agent, whose intrinsic value and autonomy ought to be respected. Second is the social dimension where mutuality, inclusiveness and justice values are pursued in safeguarding the sanctity of life. Such an endeavour attempts the creation of an environment where community resilience is built even as persons advocate for public participation in healthcare during and beyond the Covid-19 pandemic. Watkins $(2018$, p. 1) puts the argument in perspective with her assertion that,

[all] the interrelated types of accompaniments [psychosocial included] require a reorientation of the subjectivity, the interpersonal practices, and the critical understanding of the accompanier so that (s)he can stand alongside others who desire listening, witnessing, advocacy, space to develop critical inquiry and research, and joint action to address desired and needed changes.

The interpersonal and relational practices ought to be ethically grounded in fighting further exclusion and mistrust ensuing from the discrepancies being witnessed among the privileged and the underprivileged, the mentally stable and the mentally challenged. Misappropriation of humanitarian aid, especially from the Chinese philanthropist Jack Ma was a sad reflection of a collapsing moral system amidst a community of persons crowded by fear of inability to provide basic needs (food, shelter, health care and education) for their loved ones.

Cognizant of the ensuing injustices, World Health Organization (2020) released a guideline entitled 'Ethics and COVID-19: resource allocation and priority-setting.' The document insisted on fair allocation of scarce resources, guided by the ethical values of transparency, inclusiveness, consistency and accountability. Respect for the human dignity of and for all is emphasized, shunning all forms of partiality and favouritism in sharing not only monetary resources but also 'vaccines and therapies.' Misappropriation of finances and humanitarian aid and failure by the political class to adhere to physical distancing were immoral actions that challenged the ethical guidelines in Kenya. The principle of fairness and/or justice which is understood to mean equality, deters aggravation of existing injustices and exclusion. The Covid-19 season, however, affirmed that being rich and politically powerful pays during a pandemic. The rich, the powerful and their relations were exposed exploiting the health care system which ought to be universal and for all. The pandemic, however, highlighted the value of inter-relational concern for each other regardless of our differences, as it spared neither.

The motivation of being driven towards better public health dimmed in an opportune time. Selfishness dominated all the institutions that were tasked with the responsibility and the mandate of protecting the populace. In such contexts, where people feel psychologically excluded, whether ill, poor or not, retaliation to objective directives occurs. In the Covid-19 context, the government and ministry of health directives are constantly being ignored, owing to the ensuing mistrust and exclusive tendencies witnessed by the citizens. The loot and disrespect portrayed by the privileged in the country counter the core ethics of psychosocial accompaniment that advocates for a dialogue that builds mutual respect and understanding, promote effective solidarity and contributes to the empowerment of those ill, poor and the marginalized (Watkins, 2015). The citizens felt let down and ignored by the very institutions that are mandated to protect and promote their wellbeing. As such, the whole process of fighting the pandemic 
becomes one of the structural injustices that creates psychosocial misery.

As fear and distress swept through the nation and its populace, so did the coronavirus, which never discriminated against anyone; rich and poor, young and old, powerful and the marginalized. The government, the ministry of health and the privileged individuals in their corporeality ought to be concretized to the principles of accompaniment, which holds on to mutual relations, bereft of power. Values of integrity, love and compassion for all build strong solidarity that transcends any economic, social, psychological, and spiritual challenges. It is a call aimed at deconstructing selfish motivations that disrupt advances to the value of the common good. The ethical founding of psychosocial accompaniment thus, ought to advocate for a horizontal, inter-relational and mutual form of deliberately opting for a compassionate inclusion guided by the values of love, justice, integrity, transparency and accountability where each takes responsibility for being each other's keeper. It encourages a bottomup approach of singling out mental instability cases by one's relations with the help of community social and health workers.

\section{CONCLUSION}

Covid-19 exposed not only injustices but it is also one of the structural injustices besides being a contagious pandemic. Selfish motives clouded the advances of preventing the spread of the coronavirus amongst the institutions mandated with the responsibility of protecting humanity, prompting serious mental issues. People committed suicide, sexual gender-based violence and teenage pregnancies surged, child marriages increased, female genital mutilation and homicides, among others, were reported. Ethical principles were flouted, giving way to not only corruption but also the growth of mistrust amongst the populace. As a result, retaliatory tendencies of opting to not only adhere to Covid-19 interventions but also disregard peoples' rights, further compromising the intrinsic value of life. The article calls out for an ethical foundation of psychosocial accompaniment, which is community-oriented, a strategy that departs from compassion embracing values of justice and mutual solidarity devoid of power differentials. This is aimed at building trust within inter-relational subjects and communities as we advocate for strengthened public participation in matters relating to mental health.

\section{REFERENCES}

Bitta, M. A., Bakolis, I., Kariuki, S. M., Nyutu, G., Mochama, G., Thornicroft, G., \& Newton, C. R. (2018). Suicide in a rural area of coastal Kenya. BMC psychiatry, 18(1), 1-8.

Brief, P. (2020). COVID-19 and the Need for Action on Mental Health. World Health Organization.

Ellner, A., Pace, C., Lee, S., Weigel, J. L., \& Farmer, P. (2013). 4 EMBRACING COMPLEXITY. Structural Approaches in Public Health.

Farmer, P. (2011). Re-imagining accompaniment: Global health and liberation theologyConversation between Paul Farmer and Father Gustavo Gutiérrez. Ford Family Series.

Goizueta, R. S. (2009). Christ our companion: Toward a theological aesthetics of liberation. Orbis Books.

Gutierrez, G. (1983). The Power of the Poor in History (Maryknoll, NY. Orbis, 4.

Jaguga, F., \& Kwobah, E. (2020). Mental health response to the COVID-19 pandemic in Kenya: a review. International journal of mental health systems, 14(1), 1-6.

Jenkins, R., Kiima, D., Njenga, F., Okonji, M., Kingora, J., Kathuku, D., \& Lock, S. (2010). Integration of mental health into primary care in Kenya. World Psychiatry, 9(2), 118.

John, N., Roy, C., Mwangi, M., Raval, N., \& McGovern, T. (2021). COVID-19 and genderbased violence (GBV): hard-to-reach women and girls, services, and programmes in Kenya. Gender \& Development, 29(1), 55-71.

Kenya Penal Code. (2012). Laws of Kenya: Penal Code. National Council for Law Reporting with the Authority of the Attorney General. Nairobi, Kenya. 
Kokonya, D. A., Khasakhala, L. I., Kuria, M., Mutiso, V., Ongecha, F. A., \& Ndetei, D. M. (2007). The challenges of human resources in mental health in Kenya. South African Psychiatry Review, 10(1), 33-36.

Marangu, E., Mansouri, F., Sands, N., Ndetei, D., Muriithi, P., Wynter, K., \& Rawson, H. (2021). Assessing mental health literacy of primary health care workers in Kenya: a cross-sectional survey. International journal of mental health systems, 15(1), 1-10.

Marangu, E., Sands, N., Rolley, J., Mansouri, F., \& Ndetei, D. (2014). Mental healthcare in Kenya: exploring optimal conditions for capacity building: opinion paper. African Journal of Primary Health Care and Family Medicine, 6(1), 1-5.

Ministry of Health (MoH). (2020). The state of mental health in Kenya: A celebration of world mental health day 2020. Ministry of Health. Nairobi, Kenya.

Mutiso, V. N., Musyimi, C. W., Tomita, A., Loeffen, L., Burns, J. K., \& Ndetei, D. M. (2018). Epidemiological patterns of mental disorders and stigma in a community household survey in urban slum and rural settings in Kenya. International Journal of Social Psychiatry, 64(2), 120-129.

Nation Media Group. (2005). National Television Channel. https://www.nationmedia.com

Ochillo, M., \& Elsie, I. (2020). Mental health implications of COVID-19 in Kenya. Europasian Journal of Medical Sciences, 2, 128-130.

Onyango, M. A., Resnick, K., Davis, A., \& Shah, R. R. (2019). Gender-based violence among adolescent girls and young women: a neglected consequence of the West African Ebola outbreak. In Pregnant in the Time of Ebola (pp. 121-132). Springer, Cham.

Pagani, O., Francis, P. A., Fleming, G. F., Walley, B. A., Viale, G., Colleoni, M., ... \& International Breast Cancer Study Group. (2020). Absolute improvements in freedom from distant recurrence to tailor adjuvant endocrine therapies for premenopausal women: results from TEXT and SOFT. Journal of Clinical Oncology, 38(12), 1293.

Plomecka, M. B., Gobbi, S., Neckels, R., Radziński, P., Skórko, B., Lazerri, S., \& Jawaid, A. (2020). Mental health impact of COVID-19: A global study of risk and resilience factors. MedRxiv. Published online May, 9.

Republic of Kenya. (2020). A comprehensive guide on Mental Health and Psychosocial Support during the COVID-19 pandemic. Ministry of Health, Nairobi, Kenya. Comprehensive-Guide on-Menta l-Health-and-Psychosocial-SupportFor-COVID-19-Pande mic-4.pdf. Accessed June 42021.

Roy, D., Tripathy, S., Kar, S. K., Sharma, N., Verma, S. K., \& Kaushal, V. (2020). Study of knowledge, attitude, anxiety \& perceived mental healthcare need in Indian population during COVID-19 pandemic. Asian journal of psychiatry, 51, 102083.

Saxena, S., Saraceno, B., \& Granstein, J. (2013). Scaling up mental health care in resource-poor settings. Improving Mental Health Care: The Global Challenge, 12-24.

Thomson, D. R., Rich, M. L., Kaigamba, F., Socci, A. R., Hakizamungu, M., Bagiruwigize, E., ... \& Franke, M. F. (2014). Community-based accompaniment and psychosocial health outcomes in HIV-infected adults in Rwanda: a prospective study. AIDS and Behavior, 18(2), 368-380.

Wang, C., Pan, R., Wan, X., Tan, Y., Xu, L., McIntyre, R. S., ... \& Ho, C. (2020). A longitudinal study on the mental health of general population during the COVID-19 epidemic in China. Brain, behavior, and immunity, 87, 40-48.

Watkins, M. (2015). Psychosocial accompaniment. Journal of Social and Political Psychology, 3(1), 324-341.

Watkins, M. (2018). Accompaniment: psychosocial, environmental, trans-species, earth. 
Woodward, I., Vongswasdi, P., \& More, E. (2015). Generational diversity at work: A systematic review of the research.

World Health Organization. (2015). Update of the Mental Health Gap Action Programme (mhGAP) guidelines for mental, neurological and substance use disorders, 2015. World Health Organization.

World Health Organization. (2020). Mental health and psychosocial considerations during the COVID-19 outbreak, March 182020 (No. WHO/2019-nCoV/MentalHealth/2020.1).

World Health Organization.

World Health Organization. (2021). Pandemic influenza preparedness framework: annual progress report, 1 January-31 December 2020. 